\title{
Average evoked potentials and the anchoring of pitch judgments*
}

\author{
VIKTOR SARRIS \\ University of Duesseldorf, Germany \\ and \\ MANFRED HAIDER, University of Vienna, Austria
}

The general finding in psychophysics that contrast effects disappear when anchors are extreme is explained in terms of diminishing "attention" to anchors that do not belong to the same class of stimulation. In a pitch experiment with $50 \mathrm{Ss}$ the hypothesis was tested and confirmed that there is a negative correlation between the amplitude of average evoked potentials to an anchor and the physical distance of the anchor from the series.

While Helson's (1964) basic model of adaptation-level (AL) theory implies that the physical locus of neutral judgment varies as a monotonic function of the anchor value, recent systematic studies have shown that for several psychophysical dimensions the empirical anchor-AL relationship is cubic in character (Sarris, $1967,1968,1969$, in press a b; Sarris et al, in press). This well established finding is interpretable in terms of a mathematical "similarity-classification model" (SC model) according to which the common contrast effect gradually disappears when anchors become psychologically extreme (Sarris, in press b). Specifically, the SC model predicts that an "extreme" anchor will no longer serve as a partial point of reference for the judgments of series stimuli.

The assumptions of the SC model tempt one to speculate that an extreme anchor loses its "attention" value. In order to obtain more substantial evidence for the hypothesis that $\mathrm{Ss}^{\prime}$ attention to different anchors varies, it was felt that the neurophysiological correlates of anchor effectiveness should be investigated in a psychophysical task. Admittedly, the concept of "attention," though possessing considerable theoretical appeal as recent neurophysiological studies on animal and human selective attentiveness have demonstrated (see, e.g., Hernández-Peón et al, 1956; Haider et al, 1964), is in need of further theoretical clarification (Egeth, 1967; Wachtel, 1967). Notwithstanding the problems involved in the use of this specific hypothetical construct, it has been argued on theoretical and pragmatic grounds alike that basic research on the naurophysiological correlates of simple

*Research was supported in part by a grant from the "Deutsche Forschungsgemeinschaft," Germany, and the "Fond zur Forderung der wissenschaftlichen Forschung," Austria. The authors wish to thank Dr. R. Goldsmith, Max-Planck-Institut fur Psychiatrie, Munich, for help in reading the manuscript. judgmental behavior is indispensible (Corso, 1967; Thompson, 1967, Chap. 1).

Since the "peak-to-peak" amplitude measure of cortical evoked potentials (CEP) is widely considered to be (among other things) a physiological indicator of attention (see, e.g., Lynn, 1966; Worden, 1966; Näätänen, 1967), it was used here to test the foregoing "attention" hypothesis of anchor effectiveness. Specifically, it was predicted that the anchor-CEP trend follows an inverted $U$ function: An anchor numerically equal to the midpoint of the series was expected to produce a maximum CEP value since here the anchor would maximally stabilize Ss' judgmental behavior; with increasing distance of the anchor from both ends of the series, the CEP measure should gradually decrease because of the anchor's diminishing cognitive relevance.

\section{METHOD}

The psychophysical test situation followed Helson's (1947) paradigm; in addition, average evoked responses were recorded.

Stimuli and Main Procedure

An experiment on pitch was chosen here since (1) the range of possible anchor variation in pitch is relatively broad, and (2) the common interaction of receptor adaptation and perceptual judgment can be avoided if sound intensity is moderately weak. The specific stimuli values corresponded closely to those in an earlier experiment (Sarris, 1969); i.e., five frequency anchors (measuring 60, 250, 550,750 , and $10,000 \mathrm{~Hz}$ ) previously found to describe fully the cubic anchor-AL relationship were used in conjunction with a $500-$ to $600-\mathrm{Hz}$ series $(500-, 533-, 566-$, $600-\mathrm{Hz}$ ) binaural presentation of sine waves via earphones at const 60 Phon being employed.

The anchor (which $S$ was instructed neither to judge nor attend to) preceded each series stimulus and remained the same throughout a given test session. The anchor was presented for $1 \mathrm{sec}$; then, after a break of $1.5 \mathrm{sec}$, one of the series stimuli was also given for $1 \mathrm{sec}$ and was judged according to a 9-step rating scale. The response time was set at $5 \mathrm{sec}$. Four pairs with the same anchor but different series stimuli being randomly presented constituted a test block. In a single session $S$ completed 26 test blocks.

The Ss (76) were male and female undergraduate psychology students who were familiar with neither the problem investigated nor a typical EEG recording session. Most Ss were tested twice: (1) under a "no anchor" condition in order to obtain both a no-anchor AL value and a control CEP measure, and (2) 14 to 20 days later, only those 50 Ss were tested again whose control CEP measures had been found to be of sufficient quality (according to the judgment of four EEG experts). In order to avoid possible carry-over effects, each of the 50 Ss was assigned randomly to one of the five anchor conditions (each experimental group thus consisting of $10 \mathrm{Ss}$ ). A given session lasted about $40 \mathrm{~min}$.

Evoked Potential Recording

The Ss, with clinically normal hearing, were each seated comfortably in a quiet EEG chamber; during the judgmental sessions monopolar recordings were taken, the active electrode being located on the vertex of the skull and the reference electrode on the left ear lobe. In the anchor experiments, EEG responses were averaged (on-line) over 104 anchor presentations (i.e., $4 \times 26$ signals; see above) by use of a computer of average transients (CAT 1000). For details on the equipment used in this EEG laboratory, see Haider (1967).

\section{RESULTS AND DISCUSSION}

First, the empirical ALs were calculated (Sarris, 1969) from the individual judgment curves for both the control session ("no anchor") and the five anchor conditions. The results are summarized in Fig. 1, which clearly shows that the anchor-AL relationship follows the predicted cubic trend; i.e., with extreme anchor, the trend approaches the respective control level K ("without-anchor" $\mathrm{AL}$ value). As expected, nonparametric trend analysis (Ferguson, 1965) yielded a highly significant value for the cubic component $(\mathrm{z}=-4.83, \mathrm{p}<.001)$. This result not only represents a cross-validation of a previous finding (Sarris, 1969) but also shows that a necessary and minimal requirement for adequate interpretation of the anchor-CEP relationship was fulfilled here.

Secondly, the amplitude of the cortical evoked responses was measured from the $N_{1}$ (negative) peak to the $P_{2}$ (positive) peak for the 50 experimental Ss. The amplitudes were then averaged separately 


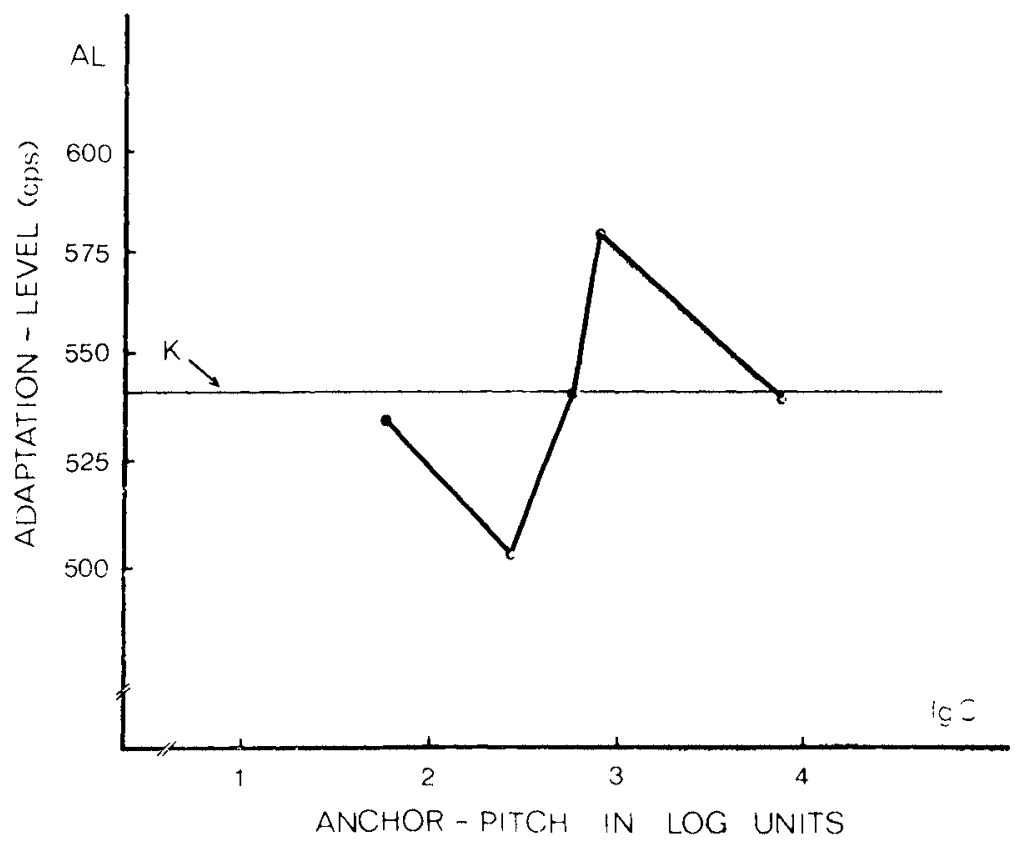

for each anchor condition over the $10 \mathrm{Ss}$. In Fig. 2, the mean CEP amplitude values (ordinate) are plotted against the five pitch anchor values $C$ (abscissa in log units of hertz). As Fig. 2 clearly shows, the anchor-CEP relationship follows the hypothesized inverted $\mathrm{U}$ trend (see above). Accordingly, nonparametric trend analysis yielded a highly significant value for the quadratic component $\quad(z=-4.14$, $\mathrm{p}<.001)$. Furthermore, in a control experiment the effect of the anchor frequencies per se (without series stimuli) was studied. In this case the same frequencies (see above) did not generate the quadratic CEP trend as shown in Fig. 2, i.e., no reliable CEP differences were found with different anchor frequencies. A more complete report of the supporting results from additional experimental checks (e.g., tests of the CEP measures from the neurophysiological reactions to the series stimuli with different anchor conditions) is given elsewhere. $^{1}$

Both the psychophysical (Fig. 1) and the neurophysiological (Fig. 2) data provide clear support for the psychological assumptions underlying the mathematical SC model: An anchor, when it becomes "extreme," no longer serves as a partial "frame of reference" for judgments of the pitch stimuli;' the extreme anchor thus appears to lose its "attention" value in

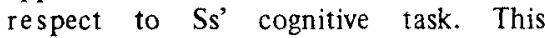
interpretation is supported as well by spontaneous comments that $S s$

Fig. 2. Mean auditory evoked potentials ("peak-to-peak" amplitude in microvolts) as a function of anchor values (in log units of hertz).
Fig. 1. Mean adaptation level as a function of anchor values (in $\log$ units of hertz).

GSR data did in fact corroborate the latter hypothesis. it appears reasonable and attractive to assume that CEP measures a cognitive "information-integration" aspect, whereas GSR measures an "arousal" aspect of attention (at least under the experimental conditions reported here). But presumably this important distinction does not hold generally (see, e.g. Näätänen, 1967). Also, data reported here seem too sparse to offer more than a tentative suggestion for an experimental at tack on the delicate problem of "attention" in psychophysics.

\section{REFERENCES}

BEVAN, W., \& DUKES, W. F. Stimulus-variation and recall: The role of belongingness. American Journal of Psychology, 1967, 80, 309.312.

CORSO, J. F. Sensory processes: Systematic developments and related data. In $\mathrm{H}$. Helson and W. Bevan (Eds.), Contemporan approaches to psychology. Princeton, N.J: D. Van Nostrand, 1967. Pp. 273-309.

occasionally made at the end of an experimental session (as for the role of "belongingness," see, e.g., Lashley \& Wade. 1946; Bevan \& Dukes, 1967). The findings here are also interesting in the light of a recent anchor study in which, ceteris paribus, GSR instead of the CEP measure was recorded (Sarris et al, in press). Since GSR seems to measure the "arousal" aspect of attention, it was expected that the anchor-GSR relationship would follow a quartic (i.e., M-shaped) trend in that those anchors that produced maximum judgmental contrast would also yield maximum GSR values and vice versa. Since

EGETH, H. E. Selective attention. Psychological Bulletin, 1967, 68, 41-57.

FERGLSON, G. A. Nonparametric trend analysis. Montreal: McGill University Press, 1965.

HAIDER, M. Vigilance, attention, expectation and cortical evoked potentials. Acta Psychologica, 1967, 27, 246-252.

HAIDER, M., SPONG, P., \& LINDSLEY, D. B. Attention, vigilance, and cortical evoked potentials in humans. Science, 1964, 145, 180-182.

HELSON, H. Adaptation-level theory. New York: Harper \& Row, 1964.

HERNANDEZ-PEÓN, R.. SCHERRER, H., \& JOUVET, M. Modification of electrical activity in cochlear nucleus during "attention" in

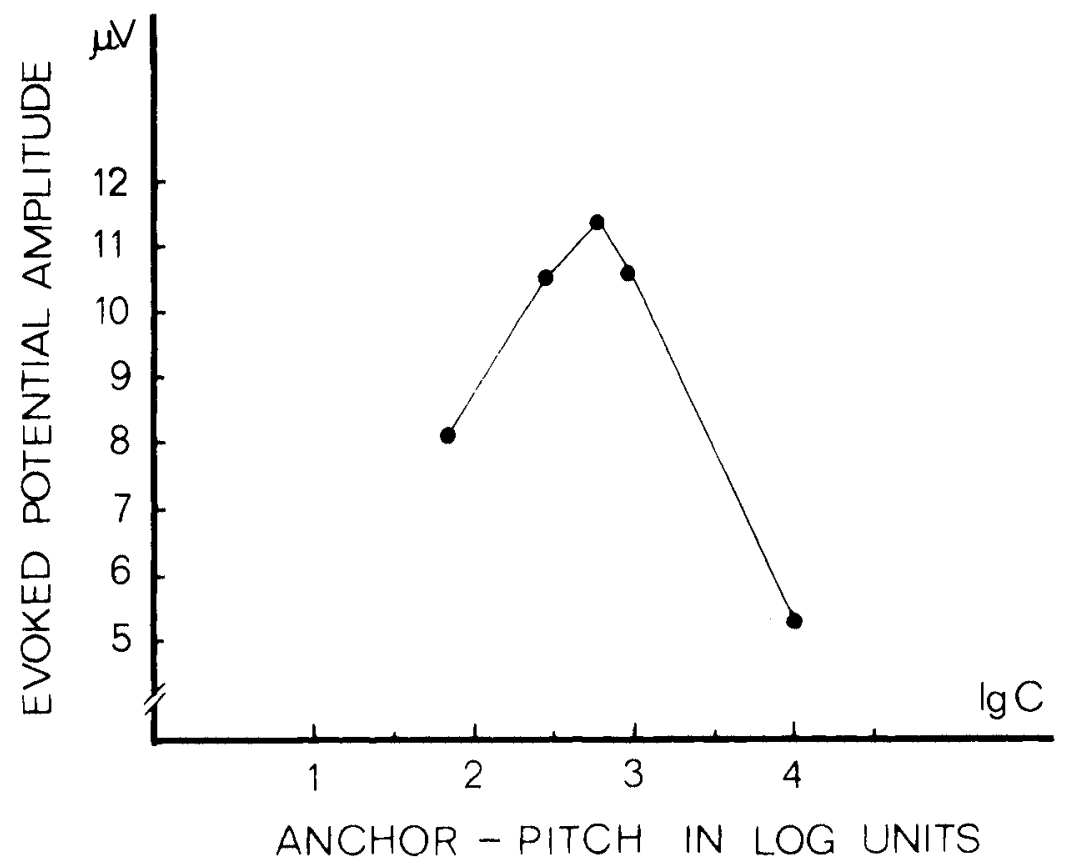

Psychon. Sci., 1970, Vol. 20 (2) 
unanesthetized cats. Science, 1956, 123 331-332.

LASHLEY, K. S., \& WADE, M. The Pavlovian theory of generalization. Psychological Review, 1946, 53, 72-87.

LYNN, R. Attention, arousal and the orienting reaction Oxford: Pergamon Press, 1966.

NÄATÄNEN, R. Selective attention and evoked potentials. Annales Academiae Scientiarum Fennicae, Series B, 151.1. Helsinki: Suomalainen Tiedeakatemia, 1967.

SARRIS, V. Adaptation-level theory: Two critical experiments on Helson's weighted average model. American Journal of Psychology, 1967, 80, 331-355.

SARRIS, V. Adaptation-level theory: Absolute or relative anchor effectiveness? Psychonomic Science, 1968, 13, 307-308.

SARRIS, V. Ankerreiz-Effekte bei Tonhohenbeurteilungen: Uberprufung des Adaptationsniveau-Modells. In M. Irle (Ed.), Bericht vom 26. Kongress der DGfP in Tubingen, 1968. Göttingen: Hogrefe, 1969. Pp. 399-405.

SARRIS, V. Anchoreffects in psychophysics: Tests on the adaptation-level model. In Reports of the XIX International Congress of
Psychology, London, 1969. In press, a

SARRIS, V. Wahrnehmung und Urteil: Bezugssystemeffekte in der Psychophysik. Gottingen: Hogrefe, in press.

SARRIS, V., TEWS, B., \& SCHONPFLUG, W. GSR and the anchoring of pitch judgments. Psychonomic Science, in press.

THOMPSON, R. F. Foundation of physiological psychology. New York: Harper \& Row, 1967.

WACHTEL, P. $\mathcal{L}$. Conceptions of broad and narrow attention. Psychological Bulletin, $1967,68,417-429$.

WORDEN, F. G. Attention and auditory electrophysiology. In E. Stellar and J. M. Sprague (Eds), Progress in physiological psychology. Vol. 1. New York: Academic Press, 1966. Pp. 45-116. NOTE

1. In addition to the main investigation reported here, 23 students served as $S s$ in an experiment to study (1) the effect of anchor frequency per se (without series stimuli), (2) the effect of instruction, and (3) the effect of stimulus-series variation on the auditory evoked responses. A full report of the corroborating results from these control experiments is given elsewhere (Sarris, in press b).

\title{
Rate of simple motor responding as a function of differential outcomes and the actual and implied presence of a coactor*
}

\author{
D. W. CARMENT \\ McMaster University, Hamilton, Ont., Canada
}

Male Ss performed a simple motor task, half alone and half coacting, under a VR 15 reinforcement schedule. Half of the coactors were paired with another $S$ on the same schedule and half with another S on a VR 5 schedule. Those performing alone could see the total reward that ostensibly had been obtained by a "previous subject." In half the cases, this "previous subject" had been on a VR 15 schedule and for the remainder on a VR 5 schedule. It was found that responding was highest among solitary Ss with lower outcomes and coactors with equal outcomes. Coactors with lower outcomes were intermediate and solitary Ss with equal outcomes responded most slowly. The importance of differential rewards and the nature of performance standards are noted.

A considerable amount of evidence has accumulated (reviewed by Zajonc, 1965,

*This research was supported by Grant No. PA0332 from the National Research Council of Canada and a grant from the Department of Labour, Government of Canada. Thanks are due Miss Judythe Little and Mr. James Alcock for their assistance. facilitated if the others present appear disinterested and unaware of the S's output (Cottrell, 1968). As Cottrell points out, these results suggest that the effects of coaction are dependent on the S's feeling that his performance in some way is being evaluated or appraised. This implies that the presence of a coactor or an audience, per se, does not enhance performance.

The experiment reported here was designed to explore this supposition. The performance of Ss alone, but aware of how a previous "subject" had performed, was contrasted with the performance of coacting Ss. Half of the Ss were paired with real or implied coactors with equal outcomes and the remainder with real or implied coactors whose outcomes were three times greater. Thus, in terms of evaluation, some Ss were led to believe that their performance was equal to that of their comparison, whereas others ostensibly performed much worse.

\section{SUBJECTS AND DESIGN}

The Ss were 40 male undergraduates chosen at random from an introductory psychology course. They were assigned randomly to four experimental conditions so that there were $10 \mathrm{Ss}$ in each condition. All Ss performed a simple motor task on a VR 15 schedule of "reinforcement." Two of the conditions included a coactor. In one of these, the coactor also was on a VR 15 schedule (coacting 15) and in the other he was on a VR 5 schedule (coacting 5). The first was intended to indicate equal levels of performance and the second that the $S$ was not performing as well as the other participant. In another two conditions, each $\mathrm{S}$ was alone but aware of the pay-off ostensibly obtained by a previous "subject." Half of these "previous subjects" had been on a VR 15 schedule (alone 15) and half on a VR 5 schedule (alone 5).

The four groups form a factorial design with two between-S factors and one within-S factor (solitary vs coacting, equal vs lower outcome, and time).

The dependent variable was the number of responses made each minute. A session lasted $5 \mathrm{~min}$.

\section{APPARATUS AND PROCEDURE}

The apparatus used was a modified Gerbrands-Lindsley conditioning panel connected to standard programming and timing units in an adjoining room. Briefly, the panel consists of two levers that can be pulled out and that are returned by an adjustable tension spring to their original position. Below each lever was a chute for the delivery of reinforcements and above each lever a counter was placed that accumulated the number of reinforcements each $S$ obtained. The reinforcements, in this case ball bearings, were placed by the $S$ 